\title{
BMJ Open Cost-utility and budget impact analyses of the use of NEPA for chemotherapy- induced nausea and vomiting prophylaxis in Italy
}

\author{
Umberto Restelli, ${ }^{1,2}$ Gabriella Saibene, ${ }^{3}$ Patrizia Nardulli, ${ }^{4}$ Roberta Di Turi, ${ }^{5}$ \\ Erminio Bonizzoni, ${ }^{6}$ Francesca Scolari, ${ }^{1}$ Tania Perrone, ${ }^{7}$ Davide Croce, ${ }^{1,2}$ \\ Luigi Celio ${ }^{3}$
}

To cite: Restelli U, Saibene G, Nardulli P, et al. Cost-utility and budget impact analyses of the use of NEPA for chemotherapyinduced nausea and vomiting prophylaxis in Italy. BMJ Open 2017;7:e015645. doi:10.1136/ bmjopen-2016-015645

- Prepublication history and additional material are available. To view these files please visit the journal online (http://dx.doi org/10.1136/bmjopen-2016015645).

Received 23 December 2016 Revised 18 May 2017 Accepted 30 June 2017

CrossMark

For numbered affiliations see end of article.

Correspondence to Dr Umberto Restelli; urestelli@gmail.com

\section{ABSTRACT}

Objective To evaluate the efficiency of resources allocation and sustainability of the use of netupitant+palonosetron (NEPA) for chemotherapyinduced nausea and vomiting (CINV) prophylaxis assuming the Italian National Health Service (NHS) perspective. A published Markov model was adapted to assess the incremental cost-utility ratio of NEPA compared with aprepitant (APR) + palonosetron (PAL0), fosaprepitant (fAPR) + PALO, APR + ondansetron (ONDA), fAPR + ONDA in patients receiving a highly emetogenic chemotherapy (HEC) and with APR + PALO and FAPR + PALO in patients receiving a moderately emetogenic chemotherapy (MEC). Setting Oncology hospital department in Italy.

Methods A Markov model was used to determine the impact of NEPA on the budget of the Italian NHS on a 5-day time horizon, corresponding to the acute and delayed CINV prophylaxis phases. Direct medical costs considered were related to antiemetic drugs, adverse events management, CINV episodes management. Clinical and quality of life data referred to previously published works. The budget impact analysis considered the aforementioned therapies plus PALO alone (for HEC and MEC) on a 5-year time horizon, comparing two scenarios: one considering the use of NEPA and one not considering its use.

Primary and secondary outcome measures Incremental cost per quality adjusted life year (QALY) and differential economic impact for the Italian NHS between the two scenarios considered.

Results NEPA is more effective and less expensive (dominant) compared with APR + PALO (for HEC and MEC), fAPR + PALO (for HEC and MEC), APR + ONDA (for HEC), fAPR + ONDA (for HEC). The use of NEPA would lead to a 5-year cost decrease of $€ 63.7$ million ( $€ 42.7$ million for $\mathrm{HEC}$ and $€ 20.9$ million for MEC).

Conclusions NEPA allows an efficient allocation of resources for the Italian NHS and it is sustainable, leading to a cost decrease compared with a scenario which does not consider its use.

\section{INTRODUCTION}

Nausea and vomiting still remain among the most feared side effects of cancer
Strengths and limitations of this study

- To the best of our knowledge, the economic analysis presented in the article is the first one concerning NEPA within the Italian context.

- The analysis conducted assessed the efficiency in resources allocation and the sustainability of antiemetic prophylaxis for patients receiving chemotherapy, which is a relevant topic in a field, as that of Oncology, in which a synthesis of effectiveness and cost containment strategies is necessary to allow accessibility of high-cost therapies.

- The generalisability of results might be limited, since the analysis was conducted concerning the Italian context.

- The Markov model used does not allow a probabilistic sensitivity analysis to be performed.

chemotherapy. ${ }^{1}$ A suboptimal control of chemotherapy-induced nausea and vomiting (CINV) can lead to delays in treatment and increase healthcare costs due to increased medication use, hospital admissions and longer hospital stays. ${ }^{2}$ Ultimately, the consequences of uncontrolled CINV can adversely impact on patient's quality of life. ${ }^{3}$

The intensity, onset and duration of CINV depend on the emetogenic potential and dose of anticancer agents as well as on individual patient characteristics. ${ }^{2}$ Highly emetogenic chemotherapy (HEC) such as cisplatin-containing regimens can result in acute emesis (within 24 hours after chemotherapy administration) in more than 90\% of patients without antiemetics. ${ }^{4}$ Agents such as carboplatin, oxaliplatin, cyclophosphamide or anthracyclines (eg, doxorubicin or epirubicin) carry a moderate emetic risk (incidence of acute emesis without antiemetics, $30 \%-90 \%$ ) as single agents but their 
combination may increase emetic risk substantially. ${ }^{4}$ The current guideline-recommended prophylaxis for patients receiving HEC is a three-drug regimen including a $5-\mathrm{HT}_{3}$ receptor antagonist $\left(5-\mathrm{HT}_{3} \mathrm{RA}\right)$, dexamethasone and a neurokinin-1 receptor antagonist (NK-1RA) ${ }^{5-7}$ In patients receiving moderately emetogenic chemotherapy (MEC), the combination of a 5- $\mathrm{HT}_{3} \mathrm{RA}$ and dexamethasone is the current guideline-recommended regimen for the prevention of CINV. ${ }^{467}$ It also should be noted that some guidelines recommend palonosetron (PALO) as the preferred 5- $\mathrm{HT}_{3} \mathrm{RA}$ in the setting of MEC. ${ }^{67}$ More recently, it has been recognised that although carboplatin is graded as moderately emetogenic in evidence-based guidelines, the emetogenic potential of this agent is at the higher end of MEC. ${ }^{8}$ Accordingly, the updated guidelines from the Multinational Association of Supportive Care in Cancer now recommend a three-drug regimen for the optimal control of CINV following carboplatin-based chemotherapy. ${ }^{4}$

Emerging from the most recent research on CINV is netupitant+palonosetron (NEPA), the first antiemetic combination drug developed. NEPA is a single oral fixed-dose combination of netupitant, a new NK-1RA with a long half life of 90 hours and PALO. ${ }^{9}$ PALO is a second-generation 5 - $\mathrm{HT}_{3} \mathrm{RA}$ that has greater 5 - $\mathrm{HT}_{3}$ receptor binding affinity and longer plasma elimination half life compared with older antagonists and a unique interaction with the 5- $\mathrm{HT}_{3}$ receptor at the molecular level. The unique pharmacology of PALO is thought to partly explain its improved efficacy against delayed CINV. ${ }^{10}$ It must be pointed out that NEPA is capable of enhancing the convenience of administering antiemetic prophylaxis targeted at two critical molecular pathways involved in the pharmacology of CINV. ${ }^{2}$ Large-scale clinical trials have demonstrated that NEPA plus dexamethasone was superior to the control combination of PALO and dexamethasone, as measured by the proportion of patients with a complete response (CR) throughout the 5-day period after the first cycle of either cisplatin-containing chemotherapy or the high-emetic-risk combination of an anthracycline and cyclophosphamide (AC) in patients with breast cancer. ${ }^{11}{ }^{12}$ It must be pointed out that the combination of AC has historically been considered a MEC regimen but because it is commonly administered to females with breast cancer, the emetogenic risk is substantially increased due to the additional patient-related risk factors (i.e., gender and age). ${ }^{25}$ Since an effective and convenient antiemetic prophylaxis that preserves benefit over repeated cycles of chemotherapy is a clinically important topic, ${ }^{13}{ }^{14}$ a double-blind, randomised phase III trial investigated the safety and efficacy of NEPA in this challenging setting. ${ }^{15}$ This study demonstrated sustained efficacy over repeated cycles of HEC or MEC in patients treated with NEPA. More recently, a multiple-cycle extension of the phase III trial with NEPA in patients with breast cancer receiving AC also showed the sustained benefit of NEPA over multiple cycles of therapy. ${ }^{16}$
The assessment of the effectiveness and safety of new treatments are two of the key dimensions that should be evaluated in the assessment of new technology. However, further impacts of the introduction of a new medicine on health services should be assessed, assuming a multidisciplinary approach as that of Health Technology Assessment (HTA). ${ }^{17}$ Within a complete HTA, the 'costs and economic evaluation' represents one of the key dimensions to be considered. The assessment of this dimension is crucial considering the context in which National Health Services worldwide are operating, characterised by a persistent stress on national healthcare budgets (i.e., austerity measures) ${ }^{18}$ and the need to make new and effective health technologies available to patients. Due to a lack of economic evaluation within the Italian National Health Service and the aforementioned considerations, the analysis presented aimed at evaluating the efficiency of resources allocation and sustainability of the use of NEPA in the management of the prophylaxis of CINV in the Italian context, both for HEC (cisplatin) and MEC (AC and non-AC MEC), through a cost-utility analysis and a budget impact analysis.

\section{METHODS}

\section{Cost-utility analysis}

Cost-utility model, perspective and model outcomes

The assessment of the incremental cost-utility ratio (ICUR) of the use of NEPA versus the comparators was performed using a Markov model already used in an analysis presented in literature, ${ }^{19}$ whose structure is reported in figure 1 . The perspective assumed in the analysis was that of the Italian National Health Service (NHS).

The model considers a single cycle of chemotherapy, with a 5-day time horizon for CINV management (no discount rate was used due to the time horizon considered) and the possibility for patients to transit through three mutually exclusive health states: 'complete protection (CP)' (absence of emetic episodes, no significant nausea ( $<25 \mathrm{~mm}$ on a Visual Analogue Scale) and no use of rescue medication), 'CR' (absence of emetic episodes and no use of rescue medication) and incomplete

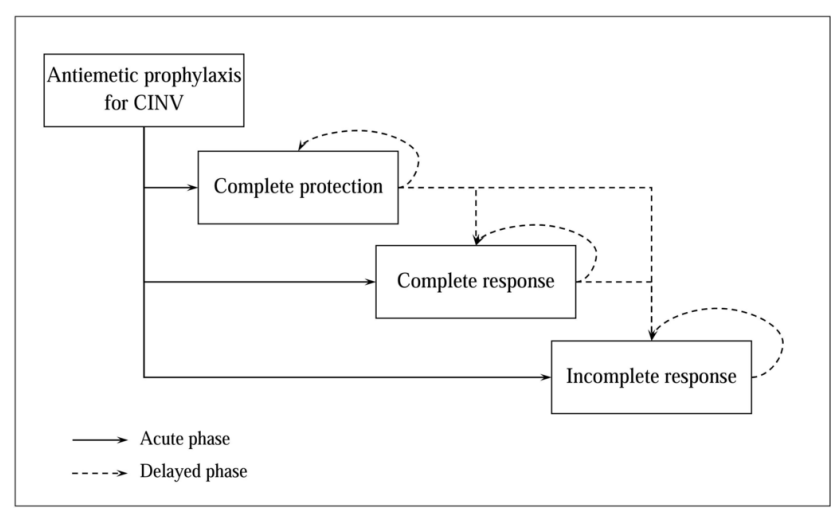

Figure 1 Markov model structure. CINV, chemotherapyinduced nausea and vomiting. 
response' (patients experiencing emesis and requiring rescue medication).

Patients who start an antiemetic prophylaxis for CINV may reach a 'CP', 'CR' or 'Incomplete response' state in the acute phase (day 1 ). On day 5 , the distribution of patients among the health states is based on the effectiveness parameters of the overall phase (day 1-5). During the second, third and fourth day, the distribution of patients among the health states was calibrated using linear interpolation between the response proportion of the acute and overall phase.

In the delayed phase (days 2-5), patients may remain in the same health state of the previous cycle or transit to 'CR' from the 'CP' state and transit to 'Incomplete response' state from the 'CP' and 'CR' health states. ${ }^{19}$

The transition probabilities depend on the effectiveness parameters considered per treatment in the acute phase and delayed phase.

During the 5-day time horizon of the analysis, patients may experience adverse events, with a probability derived from clinical trials and published studies.

The outcome of the model is the ICUR of the use of NEPA compared with each comparator. This represents the incremental cost associated with each additional unit of utility (either a QALY or a quality adjusted life day (QALD)).

\section{Interventions, eligible population and time horizon}

The cost-utility analysis was conducted considering the use of NEPA both in patients receiving HEC and MEC, comparing the use of the new drug with the administration of NK1-RA (aprepitant (APR) or fosaprepitant (fAPR)) in combination with 5HT3-RA (PALO or ondansetron (ONDA)). The time horizon considered in the analysis is of 5 days.

\section{Model parameters}

Clinical efficacy analysis

The estimates of changes in the probability of CINV control over repeated cycles of HEC or MEC were obtained from a double-blind, randomised trial of NEPAbased (day 1: NEPA plus dexamethasone) and APR-based (day 1: APR $125 \mathrm{mg}$, PALO $0.50 \mathrm{mg}$ and dexamethasone; days 2-3: APR $80 \mathrm{mg}$ per day) antiemetic regimens for the prevention of CINV among chemo-naive, adult patients with a malignancy who were scheduled to receive repeated consecutive cycle of chemotherapy. The study design has been previously described in detail. ${ }^{15}$ Four hundred and twelve patients (for a total of 1961 chemotherapy cycles, 1446 in the NEPA arm and 515 in the APR + PALO arm) were eligible, being scheduled to receive HEC or non-AC MEC regimens. The goal of the study was to characterise the safety profile of NEPA over at least six consecutive cycles of chemotherapy. Efficacy end points were CR (defined as no emesis and no rescue medication) and CP (defined as no emesis, no rescue medication and no significant nausea (Visual Analogue Scale score of $<25 \mathrm{~mm}$ )) during the acute (within 24 hours after chemotherapy administration) and overall (within 5 days after chemotherapy initiation) periods after all planned chemotherapy cycles.

The proportion of patients with either CR or CP was used to evaluate efficacy across acute and overall phases. To accurately determine protection against CINV over multiple consecutive cycles, a generalised mixed linear model was used. In detail, the overall proportions and proportions at each chemotherapy cycle of CR and CP, with associated two-tailed 95\% CIs, were estimated using a model with an identity link function (non-canonical link function), binomial probability distribution and parameterised with treatment group, cycle and treatment-by-cycle interaction as fixed effects. ${ }^{20}$ Overall CR and CP proportions were estimated directly from the generalised mixed linear model as least-square mean of the fixed effect 'treatment group'. Since incomplete profiles may occur because of the physician's decision to administer fewer than six cycles or because of drop-out events, the mixed model was parameterised using a full Toeplitz variance-covariance matrix. This should represent a suitable choice to take into account correlation across repeated measures (cycles) and to adjust for the potential bias caused by incomplete profiles. Computations were performed using the GLIMMIX procedure of SAS version 9.4.

The adjusted proportion estimates of achieving CINV control in each treatment arm during the acute and overall periods among patients receiving a cycle of HEC or MEC are presented in the online supplementary material.

The effectiveness parameters considered for NEPA are reported in table 1, along with the Odds Ratios (ORs) for each comparator, derived from the results of the NEPA study in HEC $^{11}$ and from the results of NEPA study in $\mathrm{MEC}^{12}$ ). The effectiveness parameters of NEPA, are based on the following clinical trials: the NEPA study in patients receiving either $\mathrm{HEC}$ or $\mathrm{MEC}^{15}$ and within the sensibility analysis, the NEPA studies in HEC ${ }^{11}$ and MEC. ${ }^{12}$

Starting from the effectiveness results of NEPA derived from the aforementioned clinical trial, ORs were calculated to be incorporated in the model for each comparator, as reported in table 1. Due to the clinical non-inferiority of fAPR compared with APR and to a lack of data referred to therapies that consider the use of fAPR, the same ORs of APR based therapies were considered.

The adverse events considered were constipation, headache, fatigue, injection site's reaction, anorexia. The incidence of each adverse event is reported in table 2.

\section{Costs}

The costs considered in the analysis are direct medical costs referred to year 2016 related to the antiemetic therapy administered to patients, the management of adverse events and the management of CINV episodes.

The costs related to each antiemetic drug, including the mandatory discount for the National Health Service are presented in table 3 , along with the cost per adverse event management and CINV episode management. 
Table 1 NEPA effectiveness and ORs considered in the model

\begin{tabular}{|c|c|c|c|c|c|c|}
\hline & & & \multicolumn{2}{|l|}{ Effectiveness } & \multicolumn{2}{|c|}{ NEPA versus } \\
\hline . & & & NEPA & APR + PALO & PALO*,† & APR + ONDA† \\
\hline \multirow[t]{3}{*}{ HEC } & Acute phase & Complete response & 92.8 & $1.952 \ddagger$ & 7.540 & 3.602 \\
\hline & Overall phase & Complete response & 83.6 & $1.982 \ddagger$ & 2.647 & 1.333 \\
\hline & & Complete protection & 78.0 & $2.064 \ddagger$ & 2.102 & 1.345 \\
\hline \multirow{3}{*}{ MEC } & & Complete protection & 92.8 & $1.099 \ddagger$ & 1.084 & N/A \\
\hline & Overall phase & Complete response & 88.1 & $1.248 \ddagger$ & 1.450 & N/A \\
\hline & & Complete protection & 83.5 & 1.336‡ & 1.281 & N/A \\
\hline
\end{tabular}

Due to the clinical non-inferiority of fAPR compared with APR and to a lack of data referred to therapies that imply the use of fAPR, the same ORs of APR based therapies were considered for fAPR + PALO and fAPR + ONDA.

${ }^{*}$ Considered for the budget impact analysis.

THEC: data calculated on the basis of the results from reference [11]; MEC: data calculated on the basis of the results of reference [12]. $\neq$ Data calculated on the basis of the results from reference [15].

APR, aprepitant; fAPR, fosaprepitant; HEC, highly emetogenic chemotherapy; MEC, moderately emetogenic chemotherapy; ONDA, ondansetron; PALO, palonosetron.

The cost for the management of adverse events and CINV episode are based on real clinical practice, as emerged from interviews conducted with a Key Opinion Leader clinician referring to the Department of Medical Oncology of an oncology research hospital ('Istituto di Ricovero e Cura a Carattere Scientifico') based in Milan. CINV management took into consideration a weighted mean cost which considered hospitalisations, rescue medication and outpatient activities. The management of adverse events took into consideration hospitalisations, outpatient activities and drugs. Assuming the Italian National Health Service point of view, all out-ofpocket expenditures for the management of adverse events were not considered, leading to cost equal to $€ 0$ for three of the adverse events considered in the analysis.

A further cost of $€ 20.66$ (reimbursement due to a specialist visit) was considered for intravenous administration of drugs, due to the hospital resourcesdata-word-spacing $=" 0.63 \mathrm{w}$ "' increased use compared with oral administration of therapies.

\section{Utility}

Utility was measured considering the QALYs gained by patients due to the use of antiemetic therapies. Due to the short-term time horizon considered, to increase the readability of the results, QALDs were used.

Table 2 Adverse events' incidence

\begin{tabular}{|c|c|c|c|c|c|c|}
\hline Therapy & Chemotherapy & Constipation & Headache & Fatigue & $\begin{array}{l}\text { Injection site's } \\
\text { reaction }\end{array}$ & Anorexia \\
\hline NEPA & HEC & $2.3 \% a$ & $1.0 \% \mathrm{a}$ & $4.0 \% \mathrm{~b}$ & $0.0 \% c$ & $0.7 \% d$ \\
\hline \multirow[t]{2}{*}{ APR + PALO } & HEC & $0.0 \%$ e & $1.0 \% \mathrm{e}$ & $1.4 \% \mathrm{e}$ & $0.0 \% f$ & $2.0 \% \mathrm{e}$ \\
\hline & MEC & $0.0 \% \mathrm{e}$ & $1.0 \% \mathrm{e}$ & $1.4 \% \mathrm{e}$ & $0.0 \% f$ & $2.0 \% \mathrm{e}$ \\
\hline \multirow[t]{2}{*}{ fAPR + PALO } & HEC & $2.4 \% e$ & $2.0 \% \mathrm{e}$ & $1.4 \% \mathrm{e}$ & $3.0 \% \mathrm{~g}$ & $2.0 \% \mathrm{e}$ \\
\hline & MEC & $2.4 \% \mathrm{e}$ & $2.0 \% \mathrm{e}$ & $1.4 \%$ e & $35.0 \% \mathrm{~g}$ & $2.0 \% \mathrm{e}$ \\
\hline fAPR + ONDA & HEC & $2.4 \% \mathrm{e}$ & $1.5 \% d$ & $1.4 \% \mathrm{e}$ & $3.0 \% \mathrm{~g}$ & $2.0 \% \mathrm{e}$ \\
\hline \multirow[t]{2}{*}{ PALO } & HEC & $0.0 \%{ }^{*} \dagger$ & $1.5 \% \mathrm{~d} \dagger$ & $2.0 \% \mathrm{~b} \dagger$ & $0.0 \% \mathrm{f} \dagger$ & $2.2 \% \mathrm{~d} \dagger$ \\
\hline & MEC & $0.0 \%{ }^{*} \dagger$ & $1.5 \% \mathrm{~d} \dagger$ & $2.0 \% \mathrm{~b} \dagger$ & $0.0 \% \mathrm{f \dagger}$ & $2.2 \% \mathrm{~d} \dagger$ \\
\hline
\end{tabular}

a. $^{26} ;$ b. $^{27} ;$ c. $^{28} ;$ d. $^{29} ;$ e. $^{30} ;$ f. $^{31} ; g . .^{32}$.

${ }^{\star}$ Equal to $0.0 \%$ assuming a conservative approach.

†Considered for the budget impact analysis.

APR, aprepitant; fAPR, fosaprepitant; HEC, highly emetogenic chemotherapy; MEC, moderately emetogenic chemotherapy; ONDA, ondansetron; PALO, palonosetron. 
Table 3 Costs considered in the analysis

\section{Cost per cycle/}

event

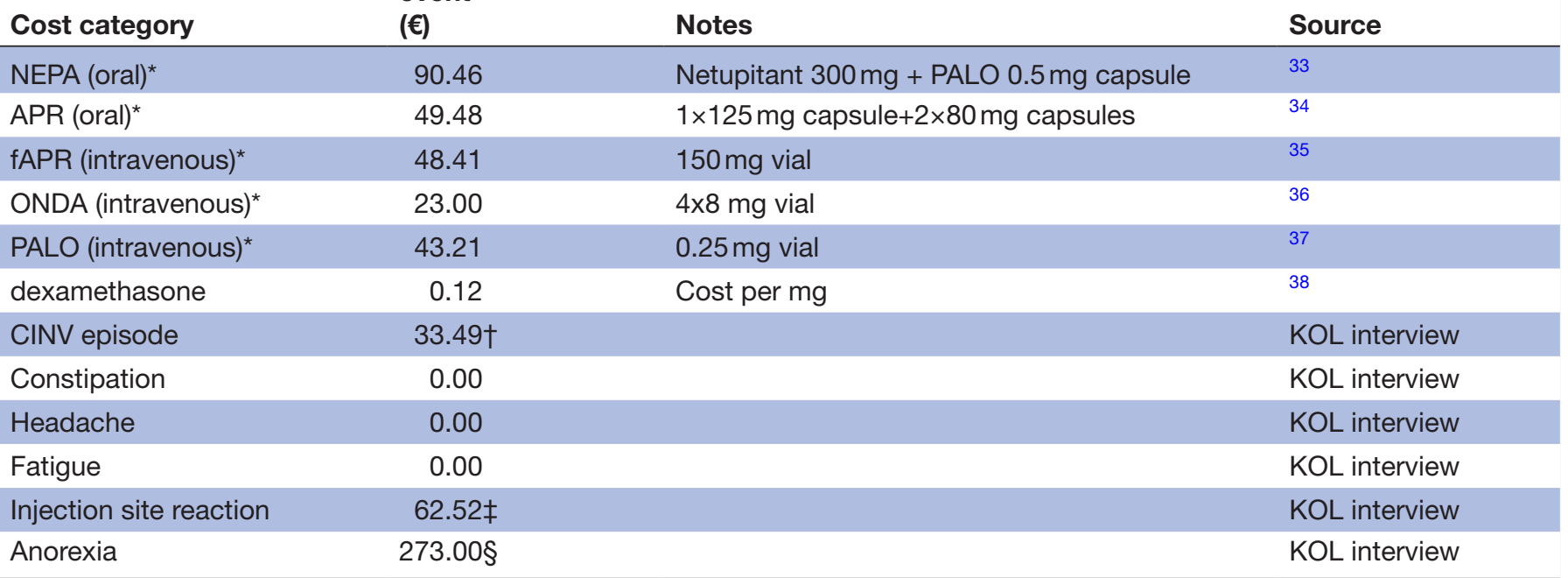

For HEC, dexamethasone doses considered are: $12 \mathrm{mg}$ in day 1 and $8 \mathrm{mg}$ on day 2,3 and 4 for NEPA, APR + PALO, APR + ONDA; $12 \mathrm{mg}$ on day $1,8 \mathrm{mg}$ in day 2 and $16 \mathrm{mg}$ on day 3 and 4 for fAPR + PALO, fAPR + ONDA; $20 \mathrm{mg}$ on day 1 and $16 \mathrm{mg}$ on day 2,3 and 4 for PALO. For MEC the dexamethasone doses considered are: $12 \mathrm{mg}$ on day 1 for NEPA, APR + PALO, fAPR + PALO, APR + ONDA, fAPR + ONDA and $20 \mathrm{mg}$ on day 1 for PALO.

${ }^{*}$ Costs are inclusive of mandatory legal discounts.

†Equivalent to a day of hospitalisation as for 'anorexia' in $2 \%$ of patients, multiplied by 5 (the hospitalisation may be repeated up to five times); a rescue medication for $10 \%$ of patients (ondansetron + metoclopramide) and a specialist visit for $5 \%$ of patients (http://www.salute. gov.it/portale/temi/p2_6.jsp?lingua=italiano\&id=3662\&area=programmazioneSanitariaLea\&menu=vuoto).

łEquivalent to the cost of 1 cannula, 30 min of nursing time, 30 min of pharmacist time and for $15 \%$ of patients, a central venous catheter positioning (code 38.95) (http://www.salute.gov.it/portale/temi/p2_6. jsp? lingua=italiano\&id=3662\&area=programmazioneSanitariaLea\&menu=vuoto).

§Equivalent to a day of hospitalisation for 'Nutrition disorders and miscellaneous metabolic disorders, $>17$ years old without complications (DRG 297)' (http://www.salute.gov.it/portale/temi/p2_6.jsp?lingua=italiano\&id=3662\&area=programmazioneSanitariaLea\&menu=vuoto). APR, aprepitant; CINV, chemotherapy-induced nausea and vomiting; fAPR, fosaprepitant; ONDA, ondansetron; PALO, palonosetron.

The quality of life of patients is affected in the model by health state and adverse events. The utility and disutility values considered are presented in table 4 .

\section{Sensitivity analysis}

A univariate sensitivity analysis was conducted to test the robustness of the results. The parameters changed were the cost of NEPA $( \pm 10 \%)$, the cost of intravenous administration (assumed to be equal to $€ 0$ ), the cost of adverse

Table 4 Utility and disutility values affecting quality of life

\begin{tabular}{lll}
\hline & $\begin{array}{l}\text { Health states' utility } \\
\text { values/adverse } \\
\text { events' disutility } \\
\text { event }\end{array}$ & Source \\
\hline values & 0.77 & 39 \\
\hline Complete protection & 0.60 & 4041 \\
\hline Incomplete response & 0.26 & 4041 \\
\hline Constipation & -0.06 & 42 \\
\hline Headache & -0.20 & 43 \\
\hline Fatigue & -0.12 & 44 \\
\hline Injection site's reaction & -0.01 & 45 \\
\hline Anorexia & -0.18 & 46 \\
\hline
\end{tabular}

events (assumed to be equal to $€ 0$ and increasing the cost of adverse events managed with out-of-pocket resources to be equal to that of the less expensive adverse event considered), the cost of CINV event $( \pm 20 \%)$, the utility values associated with health states $( \pm 20 \%)$, the disutility values associated with adverse events $( \pm 20 \%)$. A further sensitivity analysis was conducted varying the price of PALO to assess at which extent its variation could modify the results of the analysis.

\section{Budget impact analysis}

Budget impact, perspective and time horizon

The assessment of the sustainability of the use of NEPA in the Italian context was performed using a budget impact model comparing the direct medical costs related to antiemetic therapies, the management of CINV episodes and related adverse events (table 2) of two scenarios: one that did not considered the use of NEPA and one that considered the use of the new drug. The difference between the costs of the two scenarios is the impact on the budget of the Italian National Health Service due to the introduction of NEPA. The analysis was performed considering a 5-year time horizon (between 2016 and 2020). ${ }^{21}$ 
Target population, interventions' mix and market shares

The size of the target population considered was based on the incidence in Italy in 2012 of lung cancer, head and neck cancer, stomach cancer, testicular cancer and bladder cancer for patients receiving HEC; breast cancer, colorectal cancer, ovarian cancer, lung cancer, stomach cancer, pancreatic cancer for patients receiving MEC. ${ }^{22}$ The number of cycles for which NEPA might be eligible for use was derived from the international oncology guidelines of the @ sco project. $^{23}$

Due to the lack of comparative data of the use of NEPA versus ONDA for patients receiving HEC and MEC and of NEPA versus APR + ONDA and versus AAPR + ONDA for patients receiving MEC, the annual number of cycles of chemotherapies considered excludes the ones assigned to the aforementioned antiemetic treatments (ONDA for HEC and MEC; APR + ONDA and FAPR + ONDA for MEC). The market shares of each antiemetic treatment were derived starting from market analysis and KOL opinions and are reported along with the number of chemotherapy cycles considered for patients receiving HEC and MEC in the online supplementary material.

\section{Resource used and costs}

The resource used and the related costs are the same presented in the previous section ('cost-utility analysis').

\section{Sensitivity analysis}

A univariate sensitivity analysis was conducted to test the robustness of the results modifying the following parameters: effectiveness emerged in the NEPA study in HEC ${ }^{11}$ and the NEPA study in MEC, ${ }^{12}$ cost of NEPA $( \pm 10 \%)$, cost of adverse events (assumed to be equal to $€ 0$ and increasing the cost of adverse events managed with out-ofpocket resources to be equal to that of the less expensive adverse event considered), cost of CINV event $( \pm 20 \%)$.

\section{RESULTS}

\section{Cost-utility analysis}

The use of NEPA lead to a decrease of direct medical costs and to an increase of QALDs compared with APR + PALO and fAPR + PALO for patients receiving both HEC and MEC and to a decrease of direct medical costs and to an increase of QALDs compared with APR + ONDA and fAPR + ONDA for patients receiving HEC, as reported in table 5 .

NEPA dominates APR + PALO, fAPR + PALO, APR + ONDA and fAPR + ONDA in patients receiving HEC and dominates APR + PALO, fAPR + PALO in patients receiving MEC.

The sensitivity analysis conducted confirmed the robustness of the results, leading to a domination of NEPA in all the scenario considered, excluding the one in which no intravenous administration cost is considered in the analysis with APR + ONDA, in which NEPA would lead to an increase of costs and to an increase of QALDs. To evaluate whether NEPA is cost effective compared with APR + ONDA for patients receiving HEC, the $€ /$ QALD costutility ratio was converted in $€ /$ QALY. The result shows an ICUR of $€ 64329 /$ QALY. The ICUR within the population receiving HEC is on the acceptability threshold value of $€ 40000 /$ QALY identified by the Italian Association of Health Economics $;{ }^{24}$ therefore, NEPA is not cost-effective compared with APR + ONDA in the scenario that does not consider the resources used by hospitals for intravenous administration of drugs. The dominance of NEPA versus its comparators would not be affected up to a reduction of PALO price of $-63 \%$.

\section{Budget impact analysis}

In terms of impact on the budget of the Italian National Health Service, the use of NEPA is likely to lead to an annual cost decrease both for patients receiving HEC

\begin{tabular}{|c|c|c|c|c|c|c|}
\hline Chemotherapy & $\begin{array}{l}\text { Antiemetic } \\
\text { therapy }\end{array}$ & Mean cost $(€)$ & $\begin{array}{l}\text { Incremental } \\
\text { cost }(€)\end{array}$ & Mean QALDs & Incremental QALDs & $\begin{array}{l}\text { Incremental cost- } \\
\text { utility ratio ( } € / Q A L D)\end{array}$ \\
\hline \multirow[t]{8}{*}{ HEC } & APR + PALO & 132.5 & - & 2.684 & - & NEPA is dominant \\
\hline & NEPA & 102.4 & -30.2 & 2.945 & +0.261 & \\
\hline & $\mathrm{APR}+\mathrm{ONDA}$ & 148.8 & - & 3.020 & - & NEPA is dominant \\
\hline & NEPA & 100.4 & -48.4 & 3.097 & +0.077 & \\
\hline & fAPR + PALO & 155.3 & - & 2.684 & - & NEPA is dominant \\
\hline & NEPA & 102.4 & -52.9 & 2.945 & +0.261 & \\
\hline & fAPR + ONDA & 171.7 & - & 3.020 & - & NEPA is dominant \\
\hline & NEPA & 100.4 & -71.4 & 3.097 & +0.077 & \\
\hline \multirow[t]{4}{*}{ MEC } & APR + PALO & 125.1 & - & 2.992 & - & NEPA is dominant \\
\hline & NEPA & 97.9 & -27.2 & 3.044 & +0.052 & \\
\hline & fAPR + PALO & 145.9 & - & 2.992 & - & NEPA is dominant \\
\hline & NEPA & 97.9 & -48.0 & 3.044 & +0.052 & \\
\hline
\end{tabular}

APR, aprepitant; fAPR, fosaprepitant; HEC, highly emetogenic chemotherapy; MEC, moderately emetogenic chemotherapy; ONDA, ondansetron; PALO, palonosetron; QALD, quality adjusted life day. 


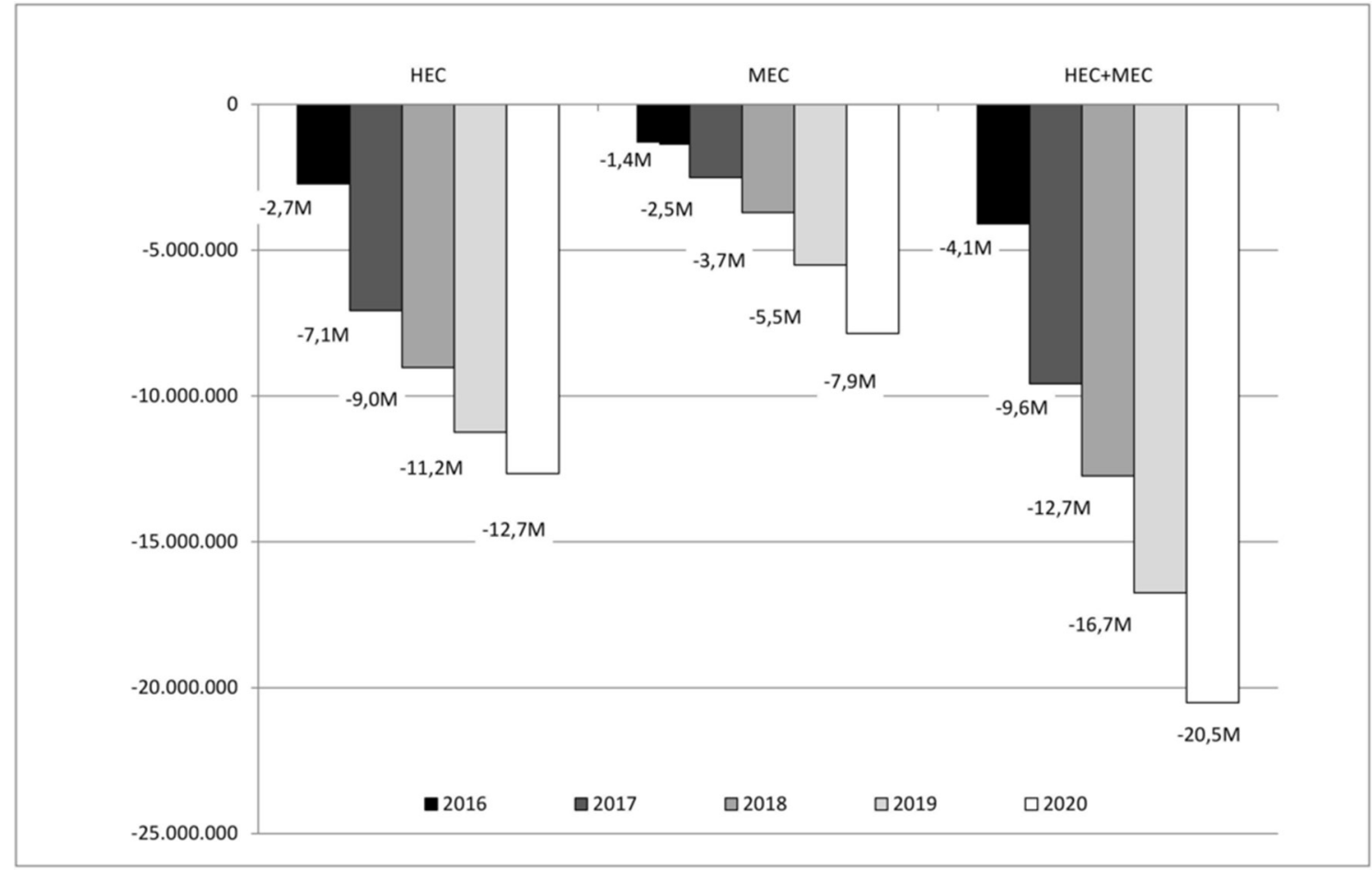

Figure 2 Budget impact analysis results.

and MEC. NEPA would lead to a 5-year cost decrease of $€ 63.7$ million (€42.7 million for patients receiving HEC and $€ 20.9$ million for patients receiving MEC). The decrease of costs for the Italian National Health Service is due to the increased use of NEPA over the years, being $€-2.7$ million in $2016, €-7.1$ million in $2017, €-9.0$ million in 2018, $€-11.2$ million in 2019 , $€-12.7$ million in 2020 for patients receiving HEC; $€-1.4$ million in 2016, €-2.5 million in 2017, €-3.7million in 2018, $€-5.5$ million in $2019, €-7.9$ million in 2020 for patients receiving MEC and $€-4.1$ million in 2016, $€-9.6$ million in $2017, €-12.7$ million in $2018, €-16.7$ million in 2019 , $€-20.5$ million in 2020 for the whole target population (HEC + MEC). The budget impact analysis results are presented in figure 2.

The results of the sensitivity analysis show a minimum 5 years budget impact of $€-49.0$ million for the whole population (HEC + MEC) in the scenario that does not consider the cost of adverse events and a maximum 5 years budget impact of $€-83.9$ million in the scenario that considers a reduction of the cost of NEPA of $10 \%$. The use of NEPA would lead to a decrease of costs for the Italian National Health Service in each year of the analysis in every scenario.

\section{DISCUSSION AND CONCLUSION}

The cost-utility analysis showed a dominance of NEPA (decreasing costs and increasing incremental QALDs) in patients receiving HEC compared with APR + PALO, fAPR + PALO, APR + ONDA and fAPR + ONDA and in patients receiving MEC compared with APR + PALO and fAPR + PALO.
In terms of sustainability of the investment, the use of NEPA would lead to a decrease of direct medical costs for the Italian National Health Service for the management of patients receiving HEC and MEC on a 5-year basis between $€-49.0$ million and $€-83.9$ million.

The sensitivity analyses conducted confirmed the robustness of results.

To our knowledge, the only economic analysis published so far concerning the use of NEPA is a poster presentation by D'Agostino and colleagues ${ }^{19}$ in which a cost effectiveness analysis was conducted comparing NEPA with APR + PALO and with PALO to prevent CINV in HEC and MEC patients in UK. NEPA dominates both APR + PALO in patients treated with HEC and PALO in patients treated with MEC and would lead to lower costs for the British NHS on a 5-year time horizon equal to $£ 13.98$ million. The results of the aforementioned study are consistent with the findings of our analysis. The lower budget impact reduction of the British study is related to the lower number of market shares considered in terms of market penetration of NEPA, due to the lower number of comparators considered. However, since drugs acquisition costs may vary considerably between countries, as the frequency of CINV episodes, international comparisons should be taken with caution. As an example, Turini and colleagues $^{25}$ estimated the direct medical costs of severe CINV episodes requiring hospitalisation in three European countries, with an average cost of $€ 389.0$ in Italy, $€ 750.1$ in France and $€ 1016.7$ in Germany.

The analysis presented took into consideration an important topic as that of antiemetic prophylaxis for patients receiving chemotherapy. The importance of 
antiemetic prophylaxis is not only related to the possibility to avoid chemotherapies' adverse events with positive effects on the quality of life of patients, on the quality of the health services' performed and on patient's management costs. The lack of prophylaxis, in fact, may lead to future anticipatory emetic events, increasing the adverse events of important and severe therapies as chemotherapy. Furthermore, such anticipatory events, might lead to further prescriptions of tranquilliser and antidepressant drugs with an increase in the drug burden for patients and of costs for the National Health Service.

Due to the expiration of the patent of PALO, generic version of this molecule might be available on the market soon. This factor would reduce the lower costs associated with the use of NEPA unless a price revision for this drug would be proposed. The sensitivity analysis results of the cost-utility Analysis show that up to a $63 \%$ reduction of the price of PALO, NEPA would remain dominant in all scenarios.

In conclusion, being aware of the limitations of the model and of the lack of a probabilistic sensitivity analysis, the use of NEPA for the prophylaxis of CINV within the Italian context would lead to an efficient allocation of resources both for the treatment of patients receiving HEC (being dominant compared with APR + PALO, fAPR + PALO, APR + ONDA and FAPR + ONDA) and MEC (being dominant compared with APR + PALO and fAPR + PALO).

The use of NEPA is sustainable in the Italian context, leading to a reduction of costs for the management of patients receiving HEC and MEC.

\section{Author affiliations \\ ${ }^{1}$ Centre for Research on Health Economics, Social and Health Care Management (CREMS), Castellanza, Italy \\ ${ }^{2}$ School of Public Health, Faculty of Health Sciences, University of the Witwatersrand, Johannesburg, South Africa \\ ${ }^{3}$ Fondazione IRCCS Istituto Nazionale Tumori, Milan, Italy \\ ${ }^{4}$ Istituto Tumori Giovanni Paolo II, IRCCS, National Cancer Institute, Bari, Italy \\ ${ }^{5}$ Dipartimento dei Servizi, Azienda Sanitaria Locale Roma 3, Rome, Italy \\ ${ }^{6}$ Department of Clinical Science and Community, Section of Medical Statistics, Biometry and Epidemiology "GA Maccacaro", University of Milan, Milan, Italy ${ }^{7}$ Department of Medical Affairs, Italfarmaco Spa, Cinisello Balsamo (MI), Italy}

Contributors UR participated in the design of the study, adapted the model, performed the economic analysis and drafted the manuscript. GS, PN, RDT and TP participated to the interpretation of the results and critically revised the article. EB participated in the design of the study, in the model adaptation and helped to draft the manuscript. FS participated in the model adaptation and economic analysis and critically revised the article. DC participated in economic analysis and critically revised the article. LC participated in the design of the study and in the adaptation of the model and helped to draft the manuscript. All authors read and approved the final manuscript.

Funding The analysis and the article drafting were supported by an unconditional grant from Italfarmaco Spa.

Competing interests UR declares advisory board fees from Bayer and Italfarmaco. GS, PN, RDT, FS and DC declare no conflict of interests. EB declares grants from Italfarmaco Spa, Zambon Spa and Polichem SA. TP is employed by Italfarmaco Spa. LC declares personal fees from Italfarmaco Spa and Helsinn Healthcare SA.

Provenance and peer review Not commissioned; externally peer reviewed.

Open Access This is an Open Access article distributed in accordance with the Creative Commons Attribution Non Commercial (CC BY-NC 4.0) license, which permits others to distribute, remix, adapt, build upon this work non-commercially, and license their derivative works on different terms, provided the original work is properly cited and the use is non-commercial. See: http://creativecommons.org/ licenses/by-nc/4.0/

(C) Article author(s) (or their employer(s) unless otherwise stated in the text of the article) 2017. All rights reserved. No commercial use is permitted unless otherwise expressly granted.

\section{REFERENCES}

1. Lorusso D, Bria E, Costantini A, et al. Patients' perception of chemotherapy side effects: expectations, doctor-patient communication and impact on quality of life - An Italian survey. Eur J Cancer Care 2017;26:e12618.

2. Hesketh PJ. Chemotherapy-induced nausea and vomiting. N Engl J Med 2008;358:2482-94.

3. de Boer-Dennert M, de Wit R, Schmitz PI, et al. Patient perceptions of the side-effects of chemotherapy: the influence of $5 \mathrm{ht} 3$ antagonists. Br J Cancer 1997;76:1055-61.

4. MASCC/ESMO, antiemetic guidelines 2016. 2016. http://www. mascc.org/antiemetic-guidelines. (accessed 10 Apr 2016).

5. Herrstedt J, Roila F, Warr D, et al. 2016 updated MASCC/ESMO consensus recommendations: prevention of nausea and Vomiting following high emetic risk chemotherapy. Support Care Cancer 2017;25:277-88.

6. Basch E, Prestrud AA, Hesketh PJ, et al. Antiemetics: American society of clinical oncology clinical practice guideline update. J Clin Oncol 2011;29:4189-98.

7. NCCN Clinical Practice guidelines in Oncology, Antiemesis v.2.2016. 2016. http://www.nccn.org. (accessed 3 Jun 2016).

8. Jordan K, Jahn F, Aapro M. Recent developments in the prevention of chemotherapy-induced nausea and vomiting (CINV): a comprehensive review. Ann Oncol 2015;26:1081-90.

9. Keating GM. Netupitant/Palonosetron: a review in the prevention of chemotherapy-induced nausea and vomiting. Drugs 2015;75:2131-41.

10. Celio L, Niger M, Ricchini F, et al. Palonosetron in the prevention of chemotherapy-induced nausea and vomiting: an evidencebased review of safety, efficacy, and place in therapy. Core Evid 2015;10:75-87.

11. Hesketh PJ, Rossi G, Rizzi G, et al. Efficacy and safety of NEPA, an oral combination of netupitant and Palonosetron, for prevention of chemotherapy-induced nausea and vomiting following highly emetogenic chemotherapy: a randomized dose-ranging pivotal study. Ann Oncol 2014;25:1340-6.

12. Aapro M, Rugo H, Rossi G, et al. A randomized phase III study evaluating the efficacy and safety of NEPA, a fixed-dose combination of netupitant and Palonosetron, for prevention of chemotherapyinduced nausea and vomiting following moderately emetogenic chemotherapy. Ann Oncol 2014;25:1328-33.

13. de Wit R, Schmitz PI, Verweij J, et al. Analysis of cumulative probabilities shows that the efficacy of $5 \mathrm{HT}_{3}$ antagonist prophylaxis is not maintained. J Clin Oncol 1996;14:644-51.

14. de Wit R, Herrstedt J, Rapoport B, et al. Addition of the oral NK1 antagonist aprepitant to standard antiemetics provides protection against nausea and vomiting during multiple cycles of cisplatinbased chemotherapy. J Clin Oncol 2003;21:4105-11.

15. Gralla RJ, Bosnjak SM, Hontsa A, et al. A phase III study evaluating the safety and efficacy of NEPA, a fixed-dose combination of netupitant and Palonosetron, for prevention of chemotherapyinduced nausea and vomiting over repeated cycles of chemotherapy. Ann Oncol 2014;25:1333-9.

16. Aapro M, Karthaus M, Schwartzberg L, et al. NEPA, a fixed oral combination of netupitant and palonosetron, improves control of chemotherapy-induced nausea and vomiting (CINV) over multiple cycles of chemotherapy: results of a randomized, double-blind, phase 3 trial versus oral palonosetron. Support Care Cancer 2017;25:1127-35.

17. EUnetHTA Joint Action 2, Work Package 8. HTA Core Model $®$ version 2.1 (Pdf). 2015. http://www.corehta.info/BrowseModel.aspx

18. Ruckert A, Labonté $R$. The global financial crisis and health equity: early experiences from Canada. Global Health 2014;10:2.

19. D'agostino $\mathrm{P}$, Cawston $\mathrm{H}$, Bourhis $\mathrm{F}$, et al. Fixed combination netupitant and palonosetron is a cost-effective intervention for the prevention of chemotherapy-induced nausea and vomiting in the Uk. Value Health 2015;18:A461.

20. Longo F, Mansueto G, Lapadula V, et al. Combination of aprepitant, palonosetron and dexamethasone as antiemetic prophylaxis in 
lung cancer patients receiving multiple cycles of cisplatin-based chemotherapy. Int J Clin Pract 2012;66:753-7.

21. Sullivan SD, Mauskopf JA, Augustovski F, et al. Budget impact analysis-principles of good practice: report of the ISPOR 2012 Budget Impact analysis good practice II Task Force. Value Health 2014;17:5-14.

22. World Health Organization. GLOBOCAN 2012: estimated cancer incidence, mortality and prevalence Worldwide. 2012 http:// globocan.iarc.fr/Pages/burden_sel.aspx.

23. Progetto @sco. Aggiornamento Delle Linee Guida Internazionali in Oncologia. https://www.progettoasco.it/category/linee-guida/ aggiornamento-delle-linee-guida-internazionali/oncologia/.

24. Italian Health Economics Association (AIES). Proposta di LineeGuida per la valutazione economica degli interventi sanitari. Politiche Sanitarie 2009;10:91-9.

25. Turini M, Piovesana V, Ruffo P, et al. An assessment of chemotherapy-induced nausea and vomiting direct costs in three EU countries. Drugs Context 2015;4:1-6.

26. Gralla R, Lichinitser M, Van Der Vegt S, et al. Palonosetron improves prevention of chemotherapy-induced nausea and vomiting following moderately emetogenic chemotherapy: results of a double-blind randomized phase III trial comparing single doses of palonosetron with ondansetron. Ann Oncol 2003;14:1570-7.

27 . Akynzeo® Prescribing Information. 2015. https://www.akynzeo. com/assets/pdf/Prescribing_Information.pdf (accessed 4 Nov 2016)

28. EMA. Akynzeo Summary of product Characteristic. http://www. ema.europa.eu/docs/en_GB/document_library/EPAR_-_Product Information/human/003728/WC500188432.pdf (accessed 3 Nov 2016).

29. Hesketh PJ, Rossi G, Rizzi G, et al. Efficacy of NEPA, a novel combination of netupitant and palonosetron of chemiotheraphy induced nausea and vomiting following highly emetogenic chemioterapy. J Clin Oncol 2013 31:578s. abstract 9512.

30. EMA. Emend Summary of product characteristics. http://www. ema.europa.eu/docs/en_GB/document_library/EPAR_-_Product Information/human/000527/WC500026537.pdf (accessed 3 Nov 2016).

31. EMA. Aloxi Summary of product characteristics. http://www. ema.europa.eu/docs/en GB/document library/EPAR - Product Information/human/000563/WC500024259.pdf (accessed 3 Nov 2016)

32. FDA. Ivemend Summary of product Characteristic. http://www. accessdata.fda.gov/drugsatfda_docs/label/2016/022023s006lbl.pdf (accessed 3 Nov 2016).

33. Agenzia Italiana del Farmaco. Determina 15 febbraio 2016. Riclassificazione Del medicinale per uso umano "Akynzeo", ai sensi dell'articolo 8, comma 10, della legge 24 dicembre 1993, n. 537. (Determina n. 245/2016). (16A01599) (GU Serie Generale n.51 del 2-3-2016). http://www.gazzettaufficiale.it/atto/serie_generale/ caricaDettaglioAtto/originario;jsessionid $=\mathrm{r} 2 \mathrm{r}+\mathrm{h} 7+\mathrm{A0NM}$ L Lm41JEk6 Bw_.ntc-as3-guri2b?atto.dataPubblicazioneGazzetta=2016-03-028 atto.codiceRedazionale $=16$ A01599\&elenco30giorni=false (accessed 3 Nov 2016).

34. Agenzia Italiana del Farmaco. Determina 30 ottobre 2014 Riclassificazione Del medicinale per uso umano «lvemend (fosaprepitant)" ai sensi dell'articolo 8, comma 10, della legge 24 dicembre 1993, n. 537. (Determina n. 1250/2014). (14A08736) (GU
Serie Generale n.265 del 14-11-2014). http://www.gazzettaufficiale. it/eli/id/2014/11/14/14A08736/sg;jsessionid=g1UFhJGio1 kuYG qwvgXPAQ_.ntc-as1-guri2a (accessed 3 Nov 2016).

35. Agenzia Italiana del Farmaco. Determina 30 ottobre 2014 Riclassificazione Del medicinale per uso umano «Ivemend (fosaprepitant)» ai sensi dell'articolo 8, comma 10, della legge 24 dicembre 1993, n. 537. (Determina n. 1250/2014). (14A08736) (GU Serie Generale n.265 del 14-11-2014). http://www.gazzettaufficiale. it/eli/id/2014/11/14/14A08736/sg;jsessionid=g1UFhJGio1 kuYG qwvgXPAQ .ntc-as1-guri2a (accessed 3 Nov 2016).

36. Agenzia Italiana del Farmaco. Comunicato. Autorizzazione all'immissione in commercio del medicinale "Ondansetrone Accord Healthcare». http://www.gazzettaufficiale.biz/atti/2011/20110108/ 11A05682.htm (accessed 3 Nov 2016).

37. Agenzia Italiana del Farmaco. Determinazione 27 febbraio 2006. regime di rimborsabilità e prezzo di vendita della specialità medicinale Aloxi «palonosetron», autorizzata con procedura centralizzata europea dalla Commissione europea. (Determinazione/C n. 82/2006) (Gazzetta n. 54 del 6 marzo 2006). http://www.gazzettaufficiale.biz/atti/2006/20060054/06A02127.htm (accessed 3 Nov 2016).

38. Agenzia Italiana del Farmaco. Autorizzazione all'immissione in commercio del medicinale «Decadron». Estratto determinazione $\mathrm{n}$. 715/2012 del 28 maggio 2012. Supplemento ordinario n. 123 alla Gazzetta Ufficiale Serie generale 141. http://www.gazzettaufficiale it/do/atto/serie generale/caricaPdf?cdimg=12A06626000000101 $10001 \& d g u=2012-06-19 \&$ art.dataPubblicazioneGazzetta $=2012-06-1$ 9\&art.codiceRedazionale $=12 \mathrm{~A} 06626 \&$ art.num $=1$ \&art.tiposerie $=S G$ (accessed 3 Nov 2016).

39. Grunberg SM, Boutin N, Ireland A, et al. Impact of nausea/vomiting on quality of life as a visual analogue scale-derived utility score. Support Care Cancer 1996;4:435-9.

40. Lordick F, Ehlken B, Ihbe-Heffinger A, et al. Health outcomes and cost-effectiveness of aprepitant in outpatients receiving antiemetic prophylaxis for highly emetogenic chemotherapy in Germany. Eur J Cancer 2007;43:299-307.

41. Annemans L, Strens D, Lox E, et al. Cost-effectiveness analysis of aprepitant in the prevention of chemotherapy-induced nausea and vomiting in Belgium. Support Care Cancer 2008;16:905-15.

42. Parker M, Haycox A, Graves J. Estimating the relationship between preference-based generic utility instruments and disease-specific quality-of-life measures in severe chronic constipation: challenges in practice. Pharmacoeconomics 2011;29:719-30.

43. Stafford MR, Hareendran A, Ng-Mak DS, et al. EQ-5DTM-derived utility values for different levels of migraine severity from a UK sample of migraineurs. Health Qual Life Outcomes 2012;10:65.

44. Attard CL, Brown S, Alloul K, et al. Cost-effectiveness of folfirinox for first-line treatment of metastatic pancreatic Cancer. Curr Oncol 2014;21:41-51.

45. Waugh N, Cummins E, Shyangdan DS, et al. Exenatide prolongedrelease suspension for injection in combination with oral antidiabetic therapy for the treatment of type 2 diabetes. National Institute for Health and Clinical Excellence, 2012.

46. Purdum AG, Globe D, Mathes A, et al. Pcn15: differences between preferences for health states: the chemotherapy adverse event selfassessed response (CAESAR) QUESTIONNAIRE. Value in Health 2001;4:89-90. 
Correction: Cost-utility and budget impact analyses of the use of NEPA for chemotherapy-induced nausea and vomiting prophylaxis in Italy

Restelli U, Saibene G, Nardulli P, et al. Cost-utility and budget impact analyses of the use of NEPA for chemotherapy-induced nausea and vomiting prophylaxis in Italy. BMJ Open 2017;7:e015645. doi: 10.1136/bmjopen-2016-015645.

There is an error in Supplementary file 1 . In the first table of the supplementary material, Annex 1, in row MEC, -2.5 and -4.4 in column ' $\triangle \mathrm{NEPA}-\mathrm{APR}+\mathrm{PALO}(\%)$ ' should be +2.5 and +4.4 , respectively.

Open Access This is an Open Access article distributed in accordance with the Creative Commons Attribution Non Commercial (CC BY-NC 4.0) license, which permits others to distribute, remix, adapt, build upon this work non-commercially, and license their derivative works on different terms, provided the original work is properly cited and the use is non-commercial. See: http://creativecommons.org/licenses/by-nc/4.0/

(C) Article author(s) (or their employer(s) unless otherwise stated in the text of the article) 2017. All rights reserved. No commercial use is permitted unless otherwise expressly granted.

BMJ Open 2017;7:e015645corr1. doi:10.1136/bmjopen-2016-015645corr1

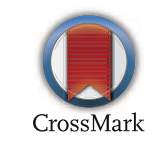

